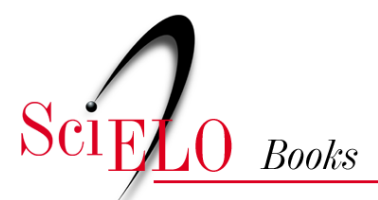

\title{
6. A Neurologia na Antiguidade
}

\author{
Joffre Marcondes de Rezende
}

\section{SciELO Books / SciELO Livros / SciELO Libros}

REZENDE, J. M. A Neurologia na Antiguidade. In: À sombra do plátano: crônicas de história da medicina [online]. São Paulo: Editora Unifesp, 2009, pp. 61-71. História da Medicina series, vol. 2. ISBN 978-85-61673-63-5. https://doi.org/10.7476/9788561673635.0007.

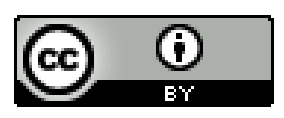

All the contents of this work, except where otherwise noted, is licensed under a Creative Commons Attribution 4.0 International license.

Todo o conteúdo deste trabalho, exceto quando houver ressalva, é publicado sob a licença Creative Commons Atribição 4.0.

Todo el contenido de esta obra, excepto donde se indique lo contrario, está bajo licencia de la licencia Creative Commons Reconocimento 4.0. 


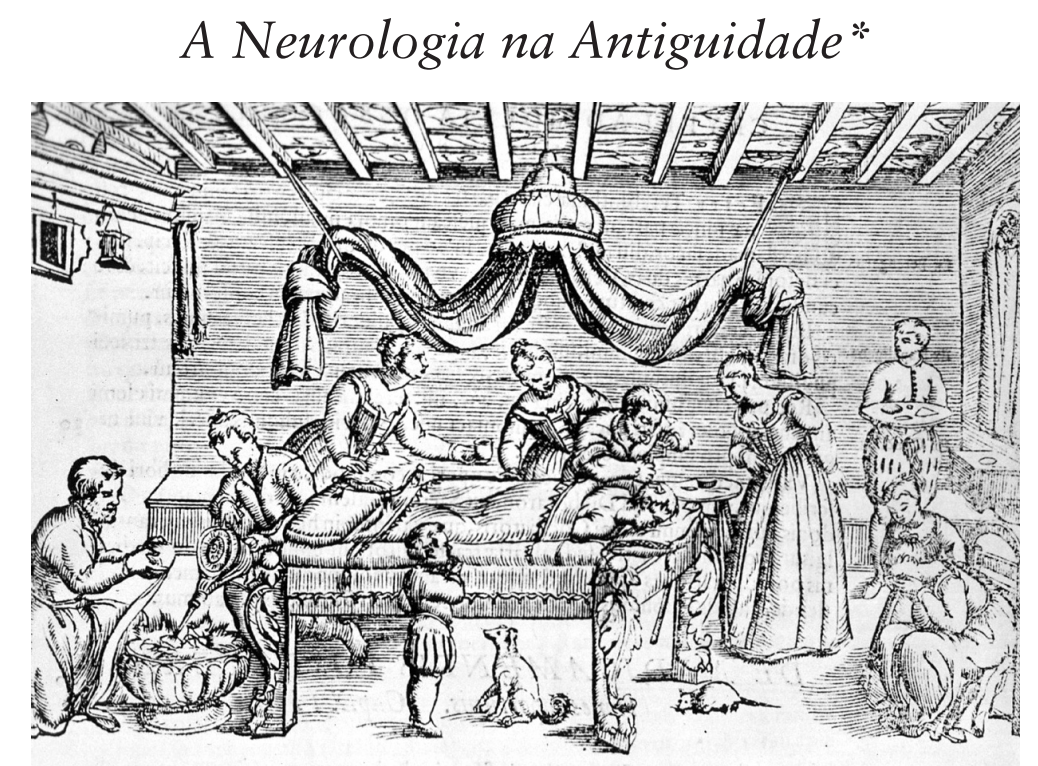

Giovanni Andrea della Croce, I5 I4-I575, retrata uma cirurgia de cabeça.

\section{Na Medicina Hipocrática}

$\mathrm{O}$ nome de neurologia, oriundo do grego neuron, nervo, e lógos, estudos, foi usado pela primeira vez por Thomas Willis, em I 664 (Lawrence Jr., I969, p. 55). Como especialidade autônoma, data do século XIX. Antes disso, desenvolveu-se lentamente, como parte da clínica médica, e encontramos os seus primórdios já na medicina da Antiguidade clássica, em particular na medicina hipocrática.

Entende-se por medicina hipocrática aquela cuja descrição se encontra na coleção de cerca de setenta livros que formam o Corpus Hippocraticum e que teriam sido escritos, em sua maioria, nos séculos v e IV a.C. Muitos desses livros são considerados de autoria do próprio Hipócrates, enquanto outros são atribuídos a discípulos seus e a outros autores (Sigerist, I96I, pp. 260-295).

* Publicado em parte na revista Neuro-Press, vol. 5, n. I, pp. I6-I7, 200I, e no Boletim da Academia Brasileira de Neurologia, 2, 2002. 
Os conhecimentos sobre o sistema nervoso na medicina hipocrática são muito deficientes. As noções de anatomia e fisiologia são precárias; sabia-se que o cérebro é formado de duas metades separadas por uma membrana e que faz continuidade com a medula espinhal. De acordo com a teoria humoral, o cérebro seria a fonte da fleuma ou pituíta, um dos quatro humores do corpo, de cujo equilíbrio, miscigenação e repartição no organismo dependeria o estado de saúde.

As meninges eram bem conhecidas pela oportunidade que oferecia o tratamento cirúrgico dos casos de traumatismo craniano. A trepanação era usada com frequência. O livro Peri ton en kephalei tromaton (Dos Ferimentos na Cabeça) dá as indicações precisas para o uso do trépano em casos de fraturas dos ossos cranianos, com instruções detalhadas sobre o manuseio do instrumento, como ilustra o seguinte passo: "Durante a operação, retira-se com frequência o trépano para mergulhá-lo em água fria por causa do seu aquecimento; o trépano aquecido determina pela rotação necrose maior do que a causada pelo trauma" (Hipócrates, I968, p. 49).

$\mathrm{O}$ atendimento dos casos de traumatismo craniano permitiu estabelecer o entrecruzamento das vias motoras em relação aos hemisférios cerebrais. No citado livro encontra-se a seguinte observação: "As convulsões aparecem na maior parte dos casos de um dos lados do corpo; se a ferida é do lado esquerdo da cabeça, as convulsões aparecem do lado direito do corpo, se a ferida é do lado direito da cabeça, aparecem do lado esquerdo do corpo. Alguns casos sucumbem em estado de apoplexia" (Idem).

O cérebro é reconhecido como o centro receptor das sensações. No livro Peri topon ton kata anthropon (Dos Lugares no Homem) encontra-se a seguinte observação a propósito dos sentidos da audição e do olfato:

A membrana meníngea é perfurada no ponto através do qual nós ouvimos. [...] Esta é a única perfuração da membrana que recobre o cérebro. Na região das narinas não há perfuração, mas uma espécie de porosidade, semelhante a uma esponja; por esta razão uma pessoa ouve a uma distância maior do que aquela em que ele sente os odores (Hipócrates, I995, p. 23).

A palavra neuron é aplicada principalmente aos tendões, que eram confundidos com os nervos. Conheciam-se apenas os nervos mais facilmente 
identificáveis como o óptico, o acústico, o trigêmeo, o vago, o plexo braquial e os nervos cubital e ciático (Lawrence Jr., I969, p. 8).

O estado de coma é mencionado em vários relatos de casos clínicos, alguns com recuperação da consciência e outros precedendo o óbito. Em qualquer situação, o coma é considerado sinal de mau prognóstico, como se lê no livro Prorretikon I.89 (Predição): "Em um paciente com respiração curta, ofegante, voz débil e que está febril, o calafrio é um sinal fatal; aqueles que estão em coma estão igualmente em mau caminho" (Hipócrates, I995, p. I88).

As manifestações neurológicas do tétano são bem caracterizadas, como no relato do seguinte caso que se encontra no livro Epidemiai pempton (Epidemias, 5):

O homem é atingido nas costas por uma seta pontiaguda, logo abaixo do pescoço; a ferida era aparentemente insignificante. Algum tempo depois de retirada a seta, no entanto, ele se estirou para trás como aqueles acometidos de opisthótonos. E sua mandíbula ficou rígida; se colocava líquido na boca e tentava deglutir, o líquido retornava pelas narinas. Seu estado se deteriorou e ele morreu dois dias depois (Hipócrates, I994, p. 43).

A disfagia faríngea em outras condições mórbidas é descrita no livro Epidemiai deuteron (Epidemias, 2): "Os doentes [...] não podem ingerir bebidas ou o fazem com dificuldade. O líquido penetra nas cavidades nasais se eles insistem. E eles têm voz nasalada" (Hipócrates, I994).

$\mathrm{Na}$ opinião de expertos na interpretação de textos do Corpus Hippocraticum, a paralisia descrita poderia corresponder à que ocorre na difteria.

A paraplegia e a tetraplegia consequentes de lesões da medula espinhal por traumatismo da coluna vertebral são referidas no livro Peri arthron, 48 (Das Articulações):

Nos casos de queda ou impacto de um grande peso geralmente há um grande deslocamento de uma ou mais vértebras, o que acarreta a morte ou produz retenção de urina e de fezes; os membros inferiores perdem calor e estas lesões são geralmente fatais. Mesmo se os pacientes sobrevivem eles apresentam incontinência da urina e têm fraqueza e torpor das pernas; quando a lesão ocorre 
mais acima há perda das forças e completo torpor de todo o corpo (Hipócrates, I968, pp. 302-305).

Um dos livros da coleção (Peri ieres nousou) é inteiramente dedicado à epilepsia, chamada na época de doença sagrada. O autor deste livro combate a ideia de uma causa sobrenatural para a epilepsia, considerando-a uma doença de causa natural, como as demais enfermidades. $\mathrm{Na}$ introdução do livro leem-se as seguintes palavras: "A doença sagrada não é mais sagrada do que as outras doenças [...] Aqueles que atribuem o caráter sobrenatural a esta doença igualam-se aos magos, encantadores, charlatães e impostores, que assumem ares de piedade e muito saber, lançando a culpa na divindade como pretexto para ocultar a sua ignorância" (Hipócrates, I967a, pp. I38-I4I).

A sede da doença é localizada no cérebro, considerado um centro importante na gênese das doenças. $\mathrm{O}$ autor admite o caráter hereditário da epilepsia e reconhece sua maior gravidade quando a mesma tem início na infância. Descreve a seguir os pródromos das crises convulsivas, o estado de mal, e menciona o aparecimento da epilepsia em adultos após traumatismos cranianos. Procura explicar a etiopatogenia da epilepsia com base na teoria humoral, que então guiava o pensamento médico e o raciocínio clínico.

As convulsões esporádicas que acompanham as hipertermias nas crianças não escaparam à observação do autor do livro Prognostikon 24 (Prognóstico): "Convulsões na vigência da febre ocorrem mais comumente em crianças de baixa idade, antes dos sete anos; crianças de mais idade e adultos não são atacados, a não ser em casos graves" (Hipócrates, 1967b, pp. 52-53).

A apoplexia que se manifesta na ausência de traumatismo craniano é mencionada no livro Peri physon (Do Ar Inspirado). O autor deste livro dá uma interpretação inteiramente fantasiosa da sua etiopatogenia. Diz ele: "A apoplexia é também causada pelo 'ar'. Quando o ar se introduz através do corpo, as partes afetadas perdem a sensibilidade. Assim, se uma grande quantidade de ar percorre o corpo inteiro, o paciente como um todo é afetado. Se o ar atinge só uma parte, somente esta parte será afetada" (Hipócrates, I967c, pp. 246-249).

São usadas três palavras para designar o "ar" - phýsa, pneuma e aer -, sendo phýsa o ar que está no corpo e aer o ar que está fora do corpo. Pneuma 
é considerado de natureza espiritual e expressa o princípio vital contido no ar, que mantém a vida através da respiração.

Desde o filósofo Anaximenes que o ar era considerado elemento essencial na constituição dos seres vivos, admitindo-se sua influência benéfica ou maléfica sobre a saúde e as doenças.

A ideia de que a apoplexia fosse causada pelo "ar" perdurou na medicina pseudocientífica oficial até o século XVIII. Na tradição oral, através das gerações, chegou até os nossos dias nas denominações populares de ar ou estupor dadas às paralisias decorrentes dos acidentes vasculares cerebrais (São Paulo, I970, pp. I 56-I 57).

A formulação teórica da medicina hipocrática não tinha base experimental e era influenciada pelas diversas escolas de pensamento filosófico da época. A patologia humoral prevaleceu como fundamento da teoria e da prática médicas por mais de dois milênios e só foi abalada no século XIX com a descoberta da estrutura celular dos seres vivos.

\section{Na Escola de Alexandria}

No período pós-hipocrático, o centro médico de maior representatividade na história da humanidade foi, sem dúvida, Alexandria. O local da cidade fora escolhido por Alexandre Magno, no braço mais ocidental do delta do rio Nilo, no ano de 323 a.C., mesmo ano em que o grande conquistador morreu de malária aos 33 anos de idade. Com a morte de Alexandre, o império por ele constituído foi dividido entre os seus generais, ficando o reino do Egito com Ptolomeu I. A cidade foi construída segundo projeto de um grande arquiteto da época, com ruas bem traçadas, perpendiculares umas às outras, e destinava-se a ser a capital do reino e a receber os restos mortais de Alexandre (Pereira, I979, p. 439).

Alexandria teve um grande desenvolvimento como centro comercial, político, cultural e científico. Ptolomeu I e seu filho e sucessor, Ptolomeu II, deram grande impulso às ciências, artes e letras, atraindo para Alexandria grandes sábios, filósofos, matemáticos, físicos, médicos, artistas, músicos e poetas.

Ptolomeu I fundou o Museu de Alexandria, que representou na civilização helenística o mesmo papel de uma grande universidade. Nele havia observatório astronômico, jardim botânico, jardim zoológico, laboratórios, 
salas para dissecção, salões de leitura e uma grande biblioteca, a maior já organizada até então, com mais de quinhentos mil volumes (rolos), abrangendo todo o conhecimento da época. Ali se encontravam cópias de todos os textos escritos pelos filósofos e pelos médicos gregos. Neste ambiente, como não poderia deixar de ser, Alexandria tornou-se um importante centro médico para onde se dirigiam os que desejavam aprender a arte médica ou nela aperfeiçoar-se. $\mathrm{Na}$ escola médica de Alexandria foram realizadas pela primeira vez dissecções públicas de corpos humanos, as quais foram posteriormente proibidas e só foram retomadas mil anos depois (Baisette, I936, p. 294; Major, I954, pp. I4 I-I45).

Dentre todos os médicos que ali se destacaram, dois nomes devem ser lembrados por seu desempenho e sua significativa contribuição ao conhecimento do sistema nervoso. São eles, Herófilo de Calcedônia (c. 300 a.C.) e Erasístrato de Chios (c. 290 a.C.). O primeiro deles filiava-se à escola de Cós e dedicou-se principalmente a estudos anatômicos; o segundo era discípulo da escola de Cnidos e preocupou-se antes com a função dos órgãos, sendo por isso considerado o pai da fisiologia. Os textos originais de Herófilo e de Erasístrato se perderam e o que hoje sabemos de suas descobertas se deve a relatos de outros autores, especialmente de Galeno.

Herófilo, ao contrário de Aristóteles, considerou o cérebro como a sede da inteligência, em lugar do coração. Descreveu a anatomia do cérebro e do cerebelo, os ventrículos, tendo valorizado a importância destas cavidades do interior do cérebro. No assoalho do quarto ventrículo descreveu o que ele comparou com a forma das penas usadas para escrever em Alexandria e que recebeu em latim a denominação de calamus scriptorius. Descreveu as meninges, às quais chamou de chorioid, pela semelhança com a membrana que envolve o feto. Deve-se a ele, igualmente, a descrição da rete mirabilis, que teria sido encontrada no cérebro de carneiro.

A estrutura do olho tornou-se melhor conhecida após suas dissecções e estudos sobre a anatomia do globo ocular e sua inervação. Reconheceu que eram os nervos e não as artérias que produziam os movimentos voluntários e estabeleceu a diferença entre os nervos motores e sensitivos, embora ainda reinasse certa confusão entre nervos motores e tendões.

Fora do sistema nervoso, a contribuição de Herófilo para o conhecimento da anatomia humana foi considerável, pois, segundo o depoimento 
de Tertuliano, Herófilo teria dissecado cerca de seiscentos corpos (Dobson, I925, pp. I9-32).

Erasístrato preocupava-se com as funções dos diferentes órgãos e aparelhos, porém também realizou dissecções e estudos anatômicos. Rejeitava todas as interferências ocultas ou sobrenaturais na gênese das doenças e procurava explicá-las por causas naturais. Não compartilhava da teoria dos quatro humores da escola hipocrática e considerava como elementos essenciais à vida apenas o sangue e dois tipos de pneuma. Segundo sua teoria, o ar inspirado era levado ao coração, onde se transformava em uma espécie peculiar de pneuma - o espírito vital, o qual era conduzido pelas artérias até ao cérebro onde se transformava em um segundo tipo de pneuma - o espírito animal, que retornava pelos nervos a todo o corpo. Esta teoria foi posteriormente desenvolvida por Galeno.

Em relação ao sistema nervoso, comparou o cérebro humano com o dos animais, verificando que a superfície cerebral no homem apresenta maior complexidade e maior número de circunvoluções, o que explicaria a superioridade da inteligência humana sobre a dos animais. Com maior segurança do que Herófilo, separou os nervos motores dos nervos sensitivos e descreveu o trajeto dos nervos dos órgãos dos sentidos (Dobson, I927, pp. 825-832).

Tanto Herófilo quanto Erasístrato foram acusados por Celsus e por Tertuliano de terem praticado a vivissecção em seres humanos, aproveitando-se de criminosos que haviam sido condenados à morte. Não há comprovação de que tal tenha ocorrido, embora ambos tenham feito vivissecção em animais (Major, op. cit.).

Após a queda da dinastia dos Ptolomeus, com Cleópatra, em 30 a.C., e o domínio do Egito pelo Império Romano, o esplendor de Alexandria entrou em lento declínio. No início do século II d.C., quando lá estudou Galeno, ainda era uma grande metrópole, com cerca de quinhentos mil habitantes. Sua grande biblioteca extinguiu-se consumida pelo fogo no século vil d.C., após a tomada de Alexandria pelos maometanos (Canfora, I989).

O próximo passo no progresso dos conhecimentos neurológicos será dado por Galeno durante o século iı d.C. 


\section{Na Obra de Galeno}

Cláudio Galeno nasceu em I 30 d.C., em Pérgamo, filho do arquiteto Nikon. Galenós, em grego, significa calmo, sereno, o que não condizia com o seu temperamento.

Galeno iniciou seus estudos médicos no Asklepeion de Pérgamo aos dezessete anos; a seguir foi para Esmirna, onde estudou dois anos e depois para Alexandria, então o maior centro cultural da civilização helenística e onde havia a maior biblioteca da época. Permaneceu cinco anos em Alexandria, onde estudou matemática, filosofia, medicina e presenciou ou teria participado de dissecções anatômicas de corpos humanos. Nessa época escreveu um dicionário geral e um dicionário médico em cinco volumes, que se perderam.

Retornou a Pérgamo, onde foi designado cirurgião do anfiteatro de gladiadores, quando teve oportunidade de observar os ferimentos e lesões decorrentes das lutas no anfiteatro. Nessa ocasião comprovou, no porco, a função do nervo recorrente.

Em I64 d.C., aos 33 anos de idade, mudou-se para Roma, onde teve muito sucesso e tornou-se médico do imperador Marco Aurélio. Permaneceu em Roma três anos, retornando a Pérgamo. Dois anos depois voltou a Roma a chamado do imperador, lá permanecendo por muitos anos. Foi médico dos dois imperadores que sucederam Marco Aurélio: Cômodo e Sétimo Severo. Ao final de sua vida, revisitou Pérgamo, viajou muito e morreu na Sicília em 200 d.C., aos setenta anos de idade (Walsh, I927, pp. I32-I43).

Durante sua permanência em Roma, Galeno desenvolveu intensa atividade: proferia conferências e palestras para o público, fazia dissecções e experiências em animais, escrevia sem cessar e era médico das classes abastadas. Sua personalidade era de um egocêntrico vaidoso e dogmático; acreditava estar sempre com a verdade e procurava contraditar seus antecessores e contemporâneos, à exceção de Hipócrates, que ele respeitava e em cuja obra e doutrina dos quatro humores se baseava para a interpretação etiopatogênica das doenças e seu tratamento.

Segundo seu próprio depoimento, teria escrito cerca de quatrocentos livros abrangendo vários campos do conhecimento, como filosofia, matemática, gramática, leis e medicina; 43 livros médicos se perderam no 
incêndio do Templo da Paz, onde seus livros encontravam-se guardados, porém foram salvos 83 . Algumas obras foram recuperadas através de traduções do árabe. O Museu Britânico possui 84 diferentes edições das obras de Galeno em latim. A coleção mais completa e a mais citada é a edição bilíngue (grego-latim), publicada por Kuhn, de I82I a I833, em 22 volumes (Major, I954, p. I92).

Com Galeno, os conhecimentos sobre o sistema nervoso tiveram um grande avanço. Ao contrário de Aristóteles, Galeno considerava o cérebro o centro das sensações e do pensamento, a sede da alma "porque nele se produz o raciocínio e se conserva a lembrança das imagens sensoriais". Estudou a anatomia do encéfalo em seus detalhes.

Descreveu sete pares de nervos cranianos, porém considerou o nervo abducente como parte do nervo óptico; o facial e o acústico (vestibulococlear) como um só nervo, assim como o glossofaríngeo e o acessório. Em realidade, Galeno só não identificou o quarto par, o nervo troclear. Descreveu igualmente trinta pares de nervos espinhais, o grande simpático tóraco-abdominal e a dupla inervação vagal e simpática dos órgãos abdominais (Galeno, I8 54 , pp. 53 I-538).

Segundo Major, Galeno foi um dos maiores neurofisiologistas de todos os tempos. Realizou várias experiências em animais, produzindo lesões no cérebro e no cerebelo e seccionando a medula espinhal em diferentes alturas e observando os efeitos resultantes.

Classificou os nervos em dois tipos: moles ou sensitivos (para os órgãos dos sentidos) e duros para os movimentos, chamando a atenção para o fato de que há órgãos com os dois tipos de nervos, como a língua e os olhos, dotados ao mesmo tempo de sensitividade e movimento. O encéfalo é o local de origem dos nervos, de toda a sensação e do movimento voluntário (Lawrence Jr., op. cit.).

Explicou a duplicidade dos órgãos dos sentidos, dos ventrículos cerebrais e dos próprios hemisférios cerebrais para a eventualidade de que "se um deles sofrer lesão, o outro suprirá a função do que for lesado" (Galeno, I 854, p. 557 ).

Combateu a ideia de Praxágoras de que as circunvoluções cerebrais são expansões da medula espinhal, visto que esta entra em contato somente com a base do cérebro, onde não há circunvoluções. 
Denominou a epífise de conarium, por seu aspecto semelhante a uma pinha (glândula pineal). Quanto à sua função, rebateu com veemência a ideia de que a mesma serve para regular a passagem do pneuma: "Esta suposição é de um espírito ignorante que se recusa a instruir-se" (Galeno, I 854, p. 565 ).

Distinguiu mais de um tipo de epilepsia, que tanto pode originar-se de uma afecção primária do encéfalo como por simpatia (oriunda de outras partes).

Referindo-se à apoplexia, considerou-a uma afecção do encéfalo, visto que todas as funções psíquicas são afetadas. Ao contrário, nos casos de simples paralisia em que a face permanece normal, a sede da lesão deve estar na medula (Galeno, I854, pp. 578-58I). Ao abordar a cefaleia e a enxaqueca (hemicrania), ressaltou que não se trata de doenças da cabeça.

Galeno estabeleceu o princípio de que toda lesão em um órgão corresponde a uma alteração da função e vice-versa. Este princípio foi o marco inicial da fisiopatologia.

Cometeu muitos erros, como o referente à sua teoria da circulação sanguínea, porém, sem nenhuma dúvida, foi o médico que maior e mais duradoura influência exerceu sobre a medicina durante nada menos de I 500 anos.

Galeno era monoteísta e sua visão sobre o corpo humano era de uma criação divina em que cada elemento anatômico fora planejado por Deus da maneira mais perfeita possível para cumprir sua função. Por esta razão, sua obra foi muito valorizada ao mesmo tempo pelos hebreus, cristãos e muçulmanos durante a Idade Média e permaneceu dogmática e intocável até a Renascença (Castiglioni, I93 I, p. I9I).

\section{Referências Bibliográficas}

Baissette, G. "L'ecole d'Alexandrie". In: Laigel-Lavastine (org.). Histoire de la médecine, 1936.

Canfora, L. A Biblioteca Desaparecida. Histórias da Biblioteca de Alexandria. São Paulo, Companhia das Letras, I989.

Castiglioni, A. Histoire de la médecine. Paris, Payot, I93 I.

Dobson, J. F. "Herophilus de Alexandria”. Proceedings of the Royal Society of Medicine. I8 mar. I925.

"Erasistratus". Proceedings of the Royal Society of Medicine. I6 fev. I927.

Entralgo, P. L. La Medicina Hipocrática. Madrid, Alianza Editorial, 1987. 
Galeno, C. Oeuvres anatomiques, physiologiques et médicales. Trad. de C. Daremberg. Paris, Baillière, I 854 . . Galeno: Procedimenti Anatomici. 3 vols., Milão, Biblioteca Universale Rizzoli, I99I.

Hipócrates. Hippocrate: Oeuvres complètes, vol. 4. Trad. E. Littré. Paris, Javal et Bourdeaux, I932.

. Hippocrates. Trad. W. H. S. Jones. Loeb Classical Library, 8 vols., Cambridge, Harvard University Press, I968-1998.

Laignel-Lavastine, A (org.). Histoire générale de la médecine, de la pharmacie, de lárt dentaire et de l'art vétérinaire. Paris, Albin Michel Ed., 1969.

Lawrence JR., C. M. Garrison's History of Neurology. Springfield, Charles C. Thomas, I969.

Liddel, H. \& Scott, R. A Greek-English Lexicon. Oxford, Claredon Press, I983.

Major, R. H. A History of Medicine. Oxford, Blackwell Scientific Publications, I954.

Pereira, M. H. R. “Estudos de História Clássica”. Cultura grega, $5^{\text {a }}$ ed., vol. I. Lisboa, Fundação Calouste Gulbenkian, I979.

São Paulo, F. Linguagem Médica Popular no Brasil. Salvador, Itapuã, I970.

Sigerist, H. E. A History of Medicine. New York, Oxford University Press, I96I, vol. I I.

Walsh, I. "Galen's studies at the alexandrian school". Annals of History of Medicine 9, 1927. 